\title{
Fostering Reflection in Academic Writing: An ELP Approach
}

Fiona Dalriel (Padova/Italy)

\section{Introduction}

The aim of this chapter is to present and illustrate a series of activities grounded in the underlying principles of the European Language Portfolio (ELP) and geared specifically to the skills involved in academic writing. The over-arching goal of these individual and collaborative tasks is to encourage learners to reflect on their skills and learning processes, adapting these to the conventions required in various genres of academic writing. What clearly lies at the basis of all steps taken is the ongoing development of metacognitive skills and strategies, strengthening the learners' ability to take a step back and look at their own academic writing and that of their peers, with a view to refining and polishing their output in order to make it fit with the demands of the respective discourse community. The fact that learners are developing skills which will allow them entry into this community highlights their role as "social agents" as discussed in the first pages of the Common European Framework of Reference (CEFR, Council of Europe 2001).

Many of the tasks described involve the use of online tools to enhance peer collaboration (see for example Dalziel 2011), which, as I will stress, should not be overlooked by teachers when adopting an ELP approach, for as Kohonen (2012: 24) reminds us: "While autonomy is ultimately a question of individual growth, its construction is enhanced by interaction." By using the term "ELP approach", I mean that ELP-based tasks should be inextricably interwoven into courses, mirroring the teacher's beliefs about language learning, or as Kohonen (2012: 23) puts it, 
"advancing language teaching towards an autonomy-oriented approach". The "pedagogical function" of the ELP has been defined as "making the language learning process more transparent to learners, helping them to develop their capacity for reflection and self-assessment, and thus enabling them gradually to assume more and more responsibility for their own learning” (Little \& Perclová 2001: 28). The ELP will not represent a valid tool if perceived by learners as something extra and not part of a given course or curriculum (Dalziel 2011); as Westhoff (2001) stresses, "an ELP without a well-elaborated and implemented pedagogical part will have little added value and will shrink to a folder with diplomas".

The article will outline five activities which can be introduced into academic writing courses. Clearly, these descriptions do not constitute a syllabus for an academic writing course, as they are merely part of a wide range of tasks aimed at developing this skill. Instead, they can be interspersed within a course, providing moments for learners "to identify learning targets, monitor progress, and evaluate outcomes" (Little 2012a: 13). Conclusions will be drawn and examples will be provided on the basis of my own experiences of teaching academic writing in a BA modern language degree course at an Italian university, but it is hoped that they are sufficiently flexible to be adapted for use in any academic writing course and with any language. Learners begin by producing a biography of their target language writing so as to position themselves at the start of this journey and to set targets specifically related to this skill; they go on to discuss the requirements of academic discourse and to create their own detailed descriptors, starting off from those of the ELP (in this case one C1 descriptor); these descriptors then form the backbone of a peer review process; and finally learners compile their own academic dossier, stating explicitly the reasons for their choices of items to include in order to maximise the pedagogical potential of this component of the ELP. The chapter will attempt to relate the proposed activities to the literature on metacognition, learner autonomy and language learning strategies on the one hand and academic writing on the other.

\section{My writing biography: where am I now?}

Using the ELP implies adopting a learner-centred approach, and the biography provides a space where learners can "set learning targets, assess their learning outcomes, and reflect on various dimensions of language learning and language use" (Little 2011: 15). At the start of any new learning experience, learners need to take stock of what they already know and "can do" and the specific areas in which they need to progress. Completing this initial reflection task will, as an academic writing course progresses, allow learners to focus on their own needs and thus derive greater benefit from the course syllabus. This can be seen as the initial phase of "Gathering of Experience/Evaluation" in the "teaching-learning cycle in the autonomy classroom" as put forward by Little, Dam and Legenhausen (2017: 16). 
However, as well as engaging the learners in a task of self-assessment, it also allows the teacher to glean valuable information about learners, their range of abilities, preferred learning styles and so on. In fact, the reflective teacher using an ELP approach will always need "to take into account the many variables occurring in language development” (Argondizzo \& Sasso 2016: 379).

The first task in any writing course can therefore simply ask learners a series of questions in order to pinpoint their present abilities and to highlight where they need to go and how they can get there. This is a task that can be carried out online in a learning environment such as Moodle. Figure One shows the instructions given to learners on how to complete the task. The task made use of Moodle's Glossary function, providing a diary-like appearance, and allowing students to read each other's entries. As can be seen, learners were invited to consult and refer to the ELP descriptors for writing when carrying out the task.

\section{Writing - Where am I now? \\ Since you started studying at university, you have done a lot of different written tasks in English. To start our course, I want you to produce a short description of these (200- 250 words), covering the following points. You can also refer to the ELP descriptors for writing (see file). \\ 1. What different types of texts you have written during your university years. \\ 2. Which types of text you find most difficult to write in English. \\ 3. What you think your level of writing ability is (B2, B2, C1 etc.). \\ 4. What you feel to be your specific strengths and weaknesses in writing and how you could improve. \\ 5. What resources (paper and online) you use when writing and how exactly you use these. \\ NB Your description should be written as a formal report, using appropriate language and paragraphing.}

Figure 1: My Writing Biography

There are multiple advantages to carrying out this activity online. First of all, it gives the task a high degree of permanence and accessibility: throughout the course, learners can go back to their initial reflections, which will help them to monitor their progress and also to set themselves new targets. As Han (2011: 201) notes when discussing online diaries, students can "time travel", viewing past targets and assessing whether or not these have been achieved. In addition, if learners are given access to their peers' Biographies, as in this case, they will be able to compare and contrast approaches and strategies and learn from each other. A series of extracts from student answers are provided below, revealing the kind of variety of levels, styles and strategies that is likely to be present in any language course. 


\begin{abstract}
Learner 1
I am a very methodical person and I have a visual memory, characteristics that have always made me consider writing the best way to learn a foreign language. Hence, I have really appreciated the opportunity I have had during my first two years of university to work on different types of texts, from the easier weekly diary, to the more formal argumentative text, passing through reports, reviews and summaries. In particular, I have found it useful to concentrate on the structure of each type of text and to focus on cohesion and fluency.
\end{abstract}

\title{
Learner 2
}

I wrote many different types of text such as reports, presentations, argumentative texts, statements of intent and learning journals. I personally found difficult to write argumentative texts at the beginning as there was a specific method to write them. Indeed, it was fundamental to learn the correct use of linking words, both how to organize the text and how to present an argument and different points of view. What I found really useful was writing learning journals so that I could keep a record of what I understood, what I learnt and which mistakes I had to avoid. This activity helped me a lot, above all to be aware of the level of my writing ability that I think is between B2 and C1.

\section{Learner 3}

In spite of the various difficulties, at the end of these two years, I believe I reached a B2 level. As a matter of fact, I can write texts on a wide range of subjects clearly and in a detailed way. However, I still have some difficulties, due to the fact that my vocabulary is not so wide, and in order to solve this weakness, I want to read more and more English texts, from the most simple to the most difficult article or book.

\section{Learner 4}

I am aware that I have some specific difficulties in writing, and one of them is related to the terminology that should be used. I need to use the dictionary or the vocabulary when I write academic texts, because I do not have a full knowledge of specific terms. As regards that particular issue, I use lots of online resources (like online dictionaries and corpora). Despite my weaknesses, I have also some strengths; for example, I use the appropriate linking words and I can write texts that are cohesive and fluent.

\section{Learner 5}

To conclude, I am happy about my English journey so far even though I am aware that there are some aspects that need improvement in order for me to reach a higher level of writing ability.

Figure 2: Examples from learners' Biographies

From the starting point of overall writing skills, however, students will need to focus on the specific demands of academic writing, in line with local course/syllabus requirements. Yet, as the extracts above clearly show, students are likely to have had experience in academic writing either during their school or higher education careers. It is thus the task of the teacher to draw on these previous experiences in exploring the genres to be developed. The following section will illustrate how this may be done. 


\section{Collaborative reflection: defining the task}

The teaching of academic writing involves gaining familiarity with one or more genres, from abstracts to reports, from biodata to the academic article, and learners need to become aware of what is expected of them in a given academic context. It is for this reason that many practitioners adopt a genre-based approach to academic writing instruction (Flowerdew 1993), an approach which, according to Hyland (2004: 5), "is concerned with what learners do when they write" and aims to introduce "the typical patterns and choices available to students in the texts they will need to write" (Hyland 2004: 12). At the same time, if a social-constructivist view is favoured, teachers will want their learners to be actively involved in the learning processes leading up to the production of a piece of writing, and to collaborate with their peers in building up their knowledge of academic genres.

When starting out on any course, it is obviously important for both teachers and students to have a clear idea of goals: the teacher needs to know what the students are being prepared for and the students will need to know what is expected of them. Yet, rather than starting by supplying descriptions and explanations of academic genres, the teacher may choose to begin by asking students to pool their already-existing knowledge and to come up with their own definitions. As the skills of argumentation lie at the basis of the production of academic discourse (Andrews 2010, Wingate 2012) and students are striving to develop their own authoritative academic voice (Hyland 2002), it would seem appropriate to engage them in producing their own definitions rather than spoon-feeding right from the start. This also fits with the emphasis on learner autonomy enshrined in the ELP, as it promotes "self-directed learning" (see for example Holec 1981, Littlewood 1996), with learners encouraged to be "proactive" (Littlewood 1999: 75). In its simplest form, the task can consist in students (individually or in small groups) answering a question such as "What is a summary?", "What is an essay?" or "What is an abstract?". Alternatively, learners can be asked to reflect on a number of different (spoken or written) genres, as in the example below. If carried out as a group task, the added benefit is that of favouring social interaction, which can, as argued by Ushioda (2003), favour the development of "motivational selfregulation". Once again, the use of an online environment makes it easy for learners to access each other's comments and for the teacher to understand better where input, consciousness-raising and scaffolding are required.

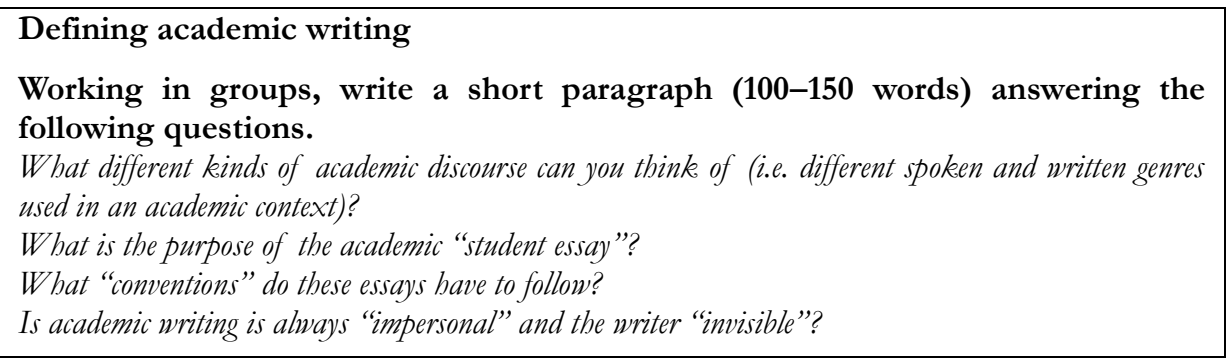




\section{Instructions:}

Click on "Add a new entry"

Write your surnames in the "Concept" box

Write your paragraph in the "Definition" box

Click on "Save changes"

Figure 3: Defining academic writing

As can be seen in the following answers to the question "What is an academic essay?", this activity can also lead to discussion of one of the most challenging aspects of academic writing, that of striking a balance between an appropriate level of impersonality and creating one's own academic stance and thorny issues such as that of authorial identity, as discussed by Hyland (2002).

\section{Example 1}

An academic essay is an informative text about different topics, written in formal register. It provides objective information according to the matter talked about. It is used for scientific, social, economic. Political and literary purposes. It relies on written sources such as historical information, lab analysis, charts, ... Usually it is written in third person because it gives us an objective point of view in order to not affect the reader's opinion. For this reason, the writer has to be impartial and avoid personal influence on the issue he is writing.

\section{Example 2}

In our opinion an academic essay is a writing genre whose aim is to convince readers of an idea based on evidence. It has a specific structure. The first paragraph is an introduction of the topic. The following paragraphs are the body of the essay where the theme is developed and thesis and antithesis are discussed, providing examples to support the writer's point of view. The next paragraph is the confutation of the antithesis. The last one is the conclusion which sums up the whole idea. The language used is formal.

\section{Example 3}

The main purpose of an academic "student essay" is to focus on a specific subject or theme. The writer has to support the main idea of the text, by giving examples and information. An essay is not always impersonal and the writer is not always "invisible", since there are different types of essays, which may require a personal or impersonal style or tone.

\section{Example 4}

To conclude in academic writing the writer is always impersonal and invisible.

Figure 4: Examples of learners' definitions (my emphasis)

After the completion of the activity, it is up to the instructor to provide feedback, and this can be done in class or online. When learning is taking place entirely online, or in the form of blended learning, teacher feedback can start off from the students' own contributions, summarizing them and only adding and commenting where necessary. This helps to define the teacher's role as that of a guide, collaborating with the learners to establish useful goals and guidelines and dealing with problematic issues, such as those related to objectivity in academic writing as seen 
above. In other words, the teacher provides scaffolding in the ongoing process of students becoming more self-directed and autonomous. It is useful here to mention the work of Oxford on language learning strategies. She points out that "learner self-direction is not an 'all or nothing' concept; it is often a gradually increasing phenomenon, growing as learners become more comfortable with the idea of their own responsibility" (Oxford 1990: 10). Some extracts from an online group feedback message can be seen below.

I enjoyed reading your definitions in this brainstorming task and think that you have, as a group, managed to cover all most important features of the academic essay. I have tried to group your ideas into different areas and added my own comments.

\subsection{Context, content and educational aims}

Your ideas:

An academic essay is a formal text written by students and academics, in which they explain their research in many fields of science, for example mathematics or literature. An academic essay is an informative text about different topics [...] used for scientific, social, economic, political and literary purposes.

An academic essay is a structured text, written or said, whose aim is to summarize and to answer a topic introduced by a question [...] It does not consist in just following a lesson, but going further and exercising their writing skills.

My comment:

What emerges from these points is that, especially in university settings, disciplinary knowledge and understanding are developed, expressed and assessed through writing. As Hyland (2002: 353) points out, academic writing revels ability to formulate ideas and put forward logical argument with "confidence and authority". In your case, you are displaying this ability in a foreign language. So, hopefully, by writing essays, you will be able both to widen your own disciplinary knowledge and develop your language skills.

Figure 5: Extracts from teacher's feedback message

Having a clear idea of genre requirements is clearly the first step in setting goals. Yet this is only one part of the writing process and the translation of task awareness into task achievement is not necessarily automatic. Once students start putting things into practice by producing academic texts, their goals will need to be monitored and revised in a dynamic process in which they attempt to find their own academic voice.

\section{Our descriptors for academic writing}

The backbone of the ELP could be considered to be its set of descriptors or "can do" statements. These are fundamental in permitting learners to develop their skills of self-assessment, which are needed to work on all parts of the portfolio: the grid in the Passport, the target-setting in the biography and even in the choice of items 
to include in the dossier. In fact, if the ELP is seen as a tool designed to mediate the CEFR to learners, the descriptors allow learners to get to grips with what is really meant by the Framework's six levels of language competence and what it entails to move from one level to another for any given skill.

Yet even in a version of the ELP designed specifically for learners in higher education (for example CercleS 2002), the descriptors cannot cover every component of the skills required for all possible use of Language for Specific Purposes (LSP) or Language for Academic Purposes. For this reason, several ELP developers (see for example Università della Calabria 2003) or practitioners have developed either portfolios or descriptors to fill this need. In fact, any version of the ELP may contain both hard and soft pages. The former are those which are fixed and a necessary component of every ELP (the Passport, the checklists of descriptors etc.), while the latter are additional parts added to fit the needs of a specific learning context. One option may be that of involving the learners themselves in the compilation of these "soft pages". This approach can easily be adopted when dealing with academic skills, as the following activity for an EAP course will demonstrate. In addition, as Little (2016: 289) argues: "At the higher proficiency levels, checklist descriptors are necessarily expressed in very general terms and need detailed deconstruction if they are to support reflective learning and selfassessment".

The course in question was aimed at third-year university students doing a BA course in modern languages, literature and culture. They had approached elements of EAP in the previous two years of their studies and the course in question had the goal of honing their academic writing skills with the ultimate task of producing an argumentative essay on a topic related to language and culture. This clearly involved gaining increased familiarity with this genre and also working on issues related to bibliographical referencing, citing and quoting, as these would then be required when writing their final $\mathrm{BA}$ dissertation (which was to be written in the target language). As the students were supposed to reach a $\mathrm{C} 1$ level in writing by the end of their degree course, they were provided with a relevant C1 descriptor and these instructions.

\section{Descriptors for academic writing}

I can write clear, well-structured texts on complex subjects in my field, underlining the relevant salient issues, expanding and supporting points of view at some length with subsidiary points, reasons and relevant examples, and rounding them off with an appropriate conclusion.

Starting off from this generic C1 descriptor, write 4 more detailed descriptors (I can ...) for the sub-skills required to write an academic essay, based on activities we have done so far.

Figure 6: Creating descriptors 
This simple task, which can be carried out collaboratively, provides an opportunity for a review of course content, and is at the same time strictly in line with the CEFR “action-oriented” approach (Council of Europe 2001: 9), giving learners the opportunity to reflect and to discuss genre requirements, rather than simply having these spelled out by the instructor. Two examples of students' proposed descripttors are shown below.

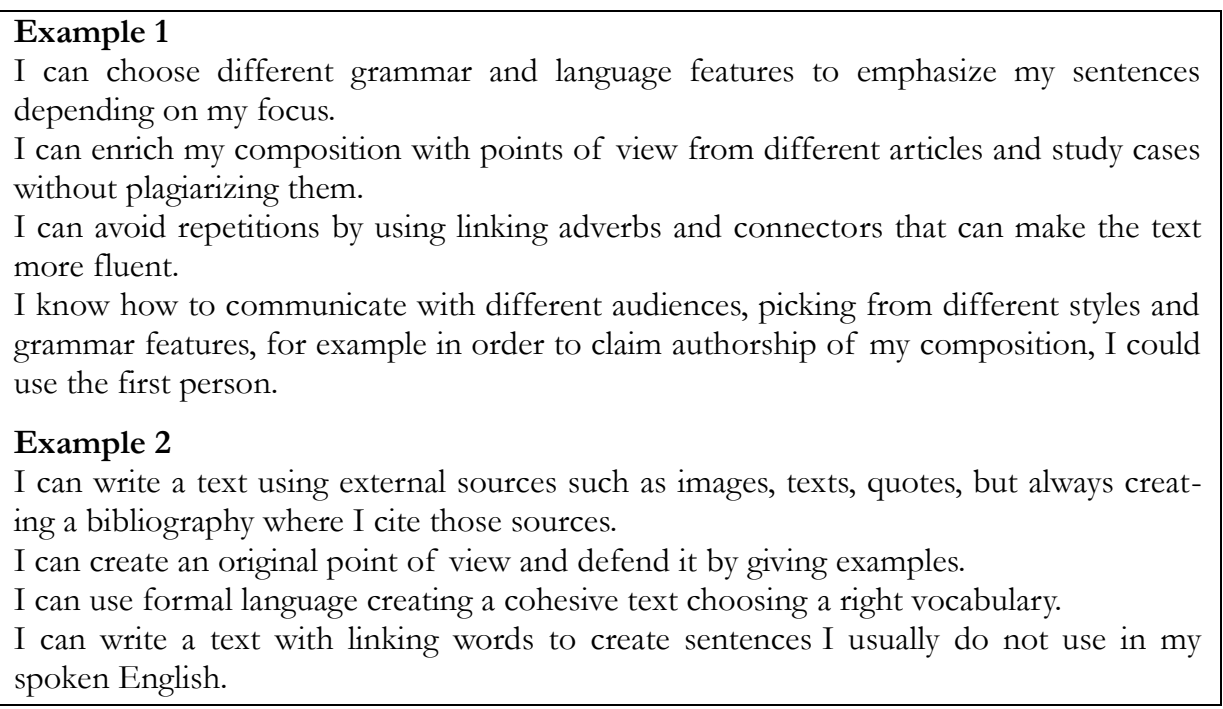

Figure 7: Learners' descriptors

As with the previous activity, the teacher may then choose to pick the "best" descriptors from each student's or group's work in order to come up with a full set. The latter can then be referred to by students in self-assessing their own academic writing and in peer review activities, such as those which will be described below. In addition, it is advisable for these learner descriptors to form the basis for the teacher's formal assessment of course outcomes as, to quote Little (2012b: 13), "we must engage students in discussion of the criteria by which their academic performance should be judged (inviting them to formulate assessment criteria is a good way of giving them insight into the nature and demands of the task in question)".

\section{$5 \quad$ Peer assessment of academic writing}

Much has been written on the value of peer review in L2 writing instruction (see for example DiGiovanni \& Nagaswami 2001, Rollinson 2005, Bijami et al. 2013, Dalziel et al. 2016) as it encourages an active, autonomous approach to learning, fosters the skills of critical thinking and provides the learner with an audience for his/her work. The concept of criticality provides a clear link between LSP and the 
ELP: when discussing reflection on learner experience, Sisamakis (2010: 363) argues that the latter "empowers the learner by seeking to find ways to help him or her to become a critical thinker capable of reflection and (self-) evaluation". There are clearly interconnections between the practice of peer assessment and that of self-assessment, which lies at the core of most ELP work. In both, it is the learner who takes a step back and evaluates language, be it his/her own work of that of a peer. As one student commented, "we had the opportunity not only to write an essay but also to read and comment those of our peers. As a consequence, by reading and commenting the texts of my peers, I could indirectly reflect on my own elaboration". Moreover, as pointed out by Carson (2010: 162), "selfassessment embedded in learning, or immediately following, and related to, a particular task (on-task rather than off-task) leads learners to self-assess more accurately".

With regard to written production, both peer and self-assessment mean being aware of the necessary communicative functions of a given text, focusing on what makes it effective or even memorable. By not merely entrusting this evaluation stage to the teacher, novice writers can be more actively involved in the learning process, perceiving gaps in proficiency and, by means of metacognition, finding short and long-term solutions and strategies to address these. As Anderson (2008: 99) observes: "Strong metacognitive skills empower language learners: when learners reflect upon their learning, they become better prepared to make conscious decisions about what they can do to improve their learning." Moreover, in the case of peer assessment, for example of academic writing, learners take on the role of readers, and thus can attempt look at the discourse from the point of view of a comember of the discourse community.

The value of peer assessment does not then merely reside in the provision of useful hints so as to improve one's writing. The reviewer him- or herself, by reading a peer's work, can come to understand more clearly what constitutes effective argumentation and the complexity of taking an academic stance and achieving identity without forfeiting objectivity. The reflections required for careful peer review will then be of use for the development of future work. In addition, if a student knows that his/her work will be read and reviewed by peers, rather than just by the writing instructor, he/she will hopefully attend more closely to aspects such as readability and creativity (trying to involve the reader) rather than concentrating on a display of linguistic ability in order to achieve a high mark.

Yet students may be resistant to such activities, not only lacking in confidence as reviewers but also unwilling to criticize the work of their peers for fear of causing offence. Any peer review activity should be orchestrated by the teacher in such a way as to avoid possible uneasiness and also be as useful and constructive as possible. This can be facilitated by giving students clear guidelines for peer review; for example, the students' descriptors (see section 4) can serve this purpose well and help learners to "break down the monolith of language learning into manageable skills and subskills" (Carson 2010: 162). 
It is also wise to stress that the goal of peer review is not one of correcting errors, but making helpful suggestions as to how written production may be improved in future, as well as commenting on what has been done well. Peer review may be organized as a oral classroom activity, but the added benefit of online peer comments is their permanence. Students can go back to them at any time during a course, searching for aspects of academic writing to concentrate on in a subsequent task or monitoring their overall progress. Two examples of online peer comments can be seen below.

\begin{abstract}
Example 1
As far as your essay is concerned, I think that overall you did quite a good job, but I have some suggestions that could help you to improve it. Firstly, I noticed that your introduction is missing a thesis statement: as a matter of fact, I could only tell what your opinion is when I read through the essay. However, I think that the introduction is the first place where your clear opinion should be stated. Secondly, I noticed that you put "Oxford, Rebecca" in your references, but you didn't cite her work in your essay. Therefore, I don't know which part is your original work and which part is taken from Oxford's article. (I read the articles too, so I can guess which part belongs to Oxford, but if an external person read your essay, then they wouldn't know it). Lastly, you could maybe cite a bit more from the articles to better support your arguments. In spite of some improvements that you could make, you wrote well and clearly and your use of linking adverbials is correct and effective.

\section{Example 2}

Hi! I found your essay generally well written. It seems that you used a correct register, correct grammatical forms as well as hedging. I appreciated your conclusion, in which you highlighted your opinion and you also quoted Kramsch as a support. However, I had the impression that your point of view and the direction you would like to give to your essay were not clearly stated in the introduction. In my opinion, you employed quotations and vocabulary well, trying to find some specific words. As regards the organisation of your text, I think you could divide the paragraphs with a blank line, so that the structure seems clearer. I would like to point out a repetition of "it" in the introduction and the absence of an "e" in "the" in the conclusion (probably a typing mistake). Anyway, your essay seems to be overall correct and logically ordered.
\end{abstract}

Figure 8: Examples of online peer comments

As can be seen, the learners in question reviewed their peers' essays from a holistic point of view, focusing on organization, citing and argumentation, but they also mentioned some elements of the lexicogrammar, such as the use of linking adverbials and spelling. It can also be noticed that both students started and ended their messages on a positive note. In fact, teachers may also want to devote time to the pragmatics of peer review, asking learners to consider how they can make constructive criticism without offending. It could be of interest here to mention that some of the strategies students adopt are similar to those of teachers, such as that of "sugaring the pill" (Hyland \& Hyland 2001). 
Another benefit of peer assessment which is in keeping with an ELP approach to language learning is that it encourages the composing of multiple drafts and thus encourages learners to reflect on the process of their (academic) writing. It is beyond the scope of this article to provide an in-depth description of approaches to second-language writing, but it is worth remembering the impact that process approaches to second-writing had on writing practices from the 1980s on (see for example Raimes 1991), drawing attention as they did to the "complex, recursive and nonlinear nature of composing" (Zamel 1987: 698). More recently, those involved in academic writing have stressed the importance of genre approaches (Tribble 1996, Hyland 2004). Nevertheless, in attempts to write texts which conform to the genre expectations of the discourse community, learners can be encouraged to focus on the non-linear, dynamic process of composing "so as to show how content, context, process, and language knowledge interrelate with each other and can be realized in practical classroom procedures" (Tribble 1996: 60). The non-linear process of composing corresponds to that of language learning itself: with an informed use of the CEFR and ELP, learners need to take on board the fact that language learning is not a simple case of moving in a linear fashion from, say A2 to B2, but rather that determining one's proficiency at any one time involves profiling "a multidimensional, interactive language system" (Lowie 2012: 31). Reflection on and awareness of such complexity is at the root of acquiring heightened autonomy and indeed of the ELP itself.

\section{My academic dossier}

The dossier section of the ELP, in which learners provide evidence of their language abilities, is perhaps the most flexible component of the tool. As stressed by Kohonen (2001), in line with the aims of the ELP as a whole, it serves both a Reporting and Pedagogical function, where the latter "provides an interface between language learning, teaching and assessment" (Kohonen 2001: 14). In order for the dossier to foster autonomy and learning, it should not be treated as a mere repository for items relating to language production, but rather as a dynamic tool, reflecting the development of skills and awareness of these. In fact, the dossier is more closely related to the biography, and overall to the concept of selfassessment, than many tend to think. In order to select which items to include in their dossiers, learners need to decide what "evidence" most aptly reflects their present level of language competence. In other words, the dossier represents the achievement of the targets set in the biography; and when these items are no longer representative of the owner's competences, they will be removed and replaced. This process of addition and removal thus mirrors the language learning narrative contained in the biography. 
As with a portfolio of any kind, the dossier can serve an array of purposes, from being a collection of pieces of work revealing the skills required for a given job, to a more introspective reflection of personal preferences and valued achievements. In all cases, though, the compilation of the dossier should require time and thought, in many ways summing up and strengthening the self-assessment processes involved in the other parts of the ELP. In the case of an academic writing course, learners can be asked to produce and update a dossier which will allow them to become part of the discourse community, for example, gaining access to a teaching programme in higher education. The items to include in the dossier need not simply be written texts, such as reports, abstracts, essays or articles, but may reflect other experiences related to the development of academic skills, participation in study groups or seminars and clearly activities such as collaborative group work projects may also be included (Mariani \& Tomai 2005: 26). It is a fundamental principle that learners themselves decide what to include in their dossiers, and if possible supply the reason for their choices (Dalziel et al. 2016).

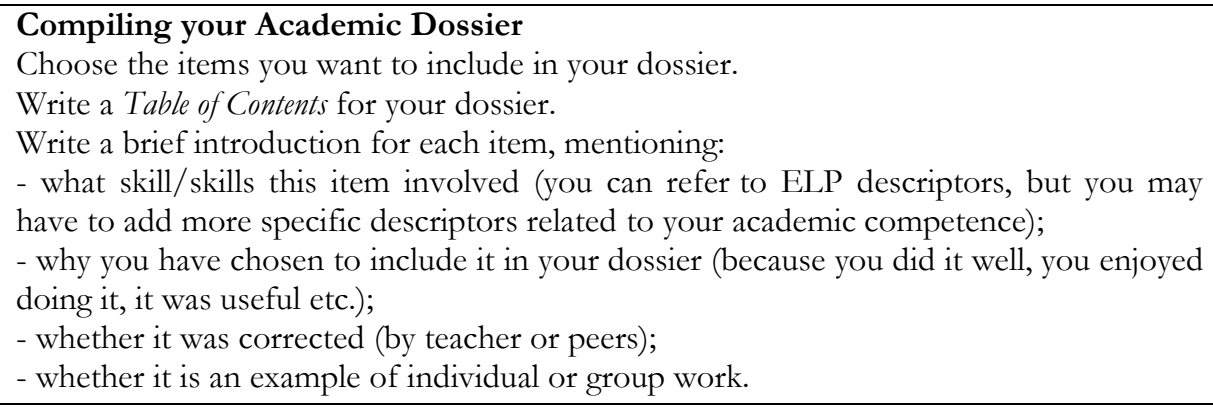

Figure 9: Instructions about dossier compilation

As can be seen, the instructions require learners to introduce the items of the dossier, relating them both to the descriptors, which involves self-assessment, but also to their language learning experiences as a whole, focusing on what they found stimulating, valuable and what they are proud of as learners. Learners should also be encouraged to take pride in the dossier itself, be it on paper or online, to pay attention the physical layout and appearance and how it could be received by a possible recipient; after all, the way that you present yourself in an academic context is of utmost importance. The examples below give a clear indication of how compiling the dossier can help learners understand the progress they have made and also think about approaches to learning such as group work and collaboration. 


\section{Learning $\log$ 1: where am I now?}

This is the first assignment of the third year for the course of Academic writing. I had to write a short description of the written task that I had done during the university years: what kinds of text I have written, what are my strengths and weaknesses and what resources I use when writing. It can be considered a B2 level; even if it was not corrected, it contains some mistakes. I choose this work because, related with the others, it highlights the changes of my writing skills during these three years.

\subsection{Report for Group Project}

During my second academic year at the University of Padua, students were asked to carry out a group project [...] The project consisted of creating a questionnaire on topics related to language and culture in order to collect data, writing a report on the data collected and give an oral presentation about what had been discovered. Since it was made up of various parts, the project involved a number of different skills. In particular, the report tested the ability to write clear and well-structured texts and to choose and describe the most important results. I have decided to include this item in my dossier because I believe that it was very useful and it helped me improve my writing skills. Furthermore, it is a good example of group work, as my peers and I decided to assign different sections to each one of us. This work was not corrected neither by other peers nor by the teacher. As I was responsible for the section about the findings, I have copied and pasted the original text here.

Figure 10: Learners' presentations of items in their dossiers

\section{Conclusion}

What I hope has emerged from the sample of ELP-based tasks outlined above is the flexibility of a tool which can be used with any group of learners with all kinds of language goals. If the aim of the teacher is that of guiding language users to higher levels of proficiency by means of empowerment, learner reflection and target language use (Little et al. 2002), then it is of no consequence whether we are concerned with A1 speaking skills or LSP for C2 level learners. As demonstrated, in any learning context, it is first necessary to give learners the opportunity to gauge their present level of competence and experience, moving on from this to polish and refine their skills by means of authentic language use, in this case academic writing. It is clear that the reflection required in ELP work complements the critical thinking skills required in academic language use and at the same time enables (high-level) learners to profile their skills. The continual self-assessment process enshrined in the ELP can be viewed as an "ecological" experience (Mariani 2009: 22), one involving the learner's personal and learning environments.

Yet, while acquiring ownership of the ELP and indeed of the learner process as a whole is a fundamental step on the path to autonomy, the teacher must provide moments for social interaction, with interdependence fostered by tasks 
such as peer review or collaborative writing. It is this interaction which will ultimately allow learners to explore, adopt and expand the use of strategies which they will then be able to transfer to other tasks, genres and environments. As Macaro (2008: 54) reminds us:

Autonomy of language learning competence, then, is having the awareness, the knowledge, and the experience of strategy use, together with the metacognition to evaluate the effectiveness not only of individual strategies, not only specific clusters against a task, but also how all these map onto a much broader canvas of language learning over time.

\section{References}

Anderson, Neil J. (2008): Metacognition and good language learners. In: Griffiths, Carol (ed.): Lessons from Good Language Learners. Cambridge: Cambridge University Press, 99-109.

Andrews, Richard (2010): Argumentation in Higher Education. Oxford: Oxford University Press.

Argondizzo, Carmen; Sasso, Maria I. (2016): The ELP through time: Background motivation, growing experience, current beliefs. In: Language Learning in Higher Education 6/2, 377-395.

Bijami, Maryam; Kashef, Seyyed Hosein; Nejad, Maryam Sharafi (2013): Peer feedback in learning English writing: advantages and disadvantages. In: Journal Studies in Education 3/4, 91-97.

Carson, Lorna (2010): Innovation and autonomy in an institution-wide language programme. In: O’Rouke, Breffni; Carson, Lorna (eds.): Language Learner Autonomy: Policy Curriculum, Classroom. A Festschrift in Honour of David Little. Bern: Lang, 151-167.

CercleS (2002): European Language Portfolio 29.2002. http:/ / elp.ecml.at/Portfolios/tabid/2370/PublicationID/144/language/en-GB/Default.aspx [01.03.2019].

Council of Europe (2001): Common European Framework of Reference for Languages: Learning, Teaching, Assessment. Cambridge: Cambridge University Press.

Dalziel, Fiona (2011): A flexible approach to the use of the European Language Portfolio in higher education contexts. In: Language Learning in Higher Education 1/1, 179-194.

Dalziel, Fiona; Davies, Gillian; Han, Amy (2016): Using the ELP as a basis for selfand peer assessment when selecting "best" work in modern-language degree programmes. In: Language Learning in Higher Education 6/2, 397-417.

DiGiovanni, Elaine; Nagaswami, Girija (2001): Online peer review: An alternative to face-to-face? In: ELT Journal 55/3, 263-272. 
Flowerdew, John (1993): An educational, or process, approach to the teaching of professional genres. In: ELT Journal 47/4, 305-316.

Han, Amy (2011): Gaining insights into reflection from online learner diaries. In: Language Learning in Higher Education 1/1, 195-210.

Holec, Henri (1981): Autonomy and Foreign Language Learning. Oxford: Pergamon.

Hyland, Fiona; Hyland, Ken (2001): Sugaring the pill. Praise and criticism in written feedback. In: Journal of Second Language Writing 10, 185-212.

Hyland, Ken (2002): Authority and invisibility: authorial identity in academic writing. In: Journal of Pragmatics 34/8, 1091-1112.

Hyland, Ken (2004): Genre and Second Language Writing. Michigan: University of Michigan Press.

Kohonen, Viljo (2001): Exploring the educational possibilities of the "Dossier": Suggestions for developing the pedagogical function of the European Language Portfolio. In: Kohonen, Viljo; Westhoff, Gerard (eds.): Enhancing the Pedagogical Aspects of the European Language Porffolio (ELP). Strasbourg: Council of Europe, 5-31. https://rm.coe.int/1680459fa2 [01.03.2019].

Kohonen, Viljo (2012): Developing autonomy through ELP-oriented pedagogy: exploring the interplay of shallow and deep structures in a major change within language education. In: Kühn, Bärbel; Pérez Cavana, María Luisa (eds.): Perspectives from the European Language Portfolio. Learner Autonomy and Self-assessment. London: Routledge, 22-42.

Little, David (2011): The Common European Framework of Reference for Languages, the European Language Portfolio, and language learning in higher education. In: Language Learning in Higher Education 1/1, 1-21.

Little, David (2012a): The European Language Portfolio: history, key concerns, future prospects. In: Kühn, Bärbel; Pérez Cavana, María Luisa (eds.): Perspectives from the European Language Portfolio. Learner Autonomy and Self-assessment. London: Routledge, 7-21.

Little, David (2012b): The Common European Framework of Reference for Languages and the European Language Portfolio: Some history, a view of language learner autonomy, and some implications for language learning in higher education. In: Language Learning in Higher Education 2/1, 1-16.

Little, David (2016): The Common European Framework of Reference for Languages, the European Language Portfolio, and language teaching/learning at university: An argument and some proposals. In: Language Learning in Higher Education 6/2, 283-296.

Little, David; Dam, Leni; Legenhausen, Lienhard (2017): Language Learner Autonomy. Theory, Practice and Research. Bristol: Multilingual Matters.

Little, David; Perclová, Radka (2001): The European Language Portfolio: a guide for teachers and teacher trainers. Strasbourg: Council of Europe. 
Little, David; Ridley, Jennifer; Ushioda, Ema (2002): Towards Greater Learner Autonomy in the Foreign Language Classroom. Dublin: Authentik.

Littlewood, William (1996): Autonomy: An anatomy and a framework. In: System 24/4, 427-435.

Littlewood, William (1999): Defining and developing autonomy in East Asian contexts. In: Applied Linguistics 20/1, 71-94.

Lowie, Wander (2012): The CEFR and the dynamics of second language learning: trends and challenges. In: Language Learning in Higher Education 2/1, 17-34.

Macaro, Ernesto (2008): The shifting dimensions of language learner autonomy. In: Lamb, Terry; Reinders, Hayo (eds.): Learner and Teacher Autonomy. Concepts, Realities, and Responses. Amsterdam: John Benjamins, 47-62.

Mariani, Luciano (2009): Il Portfolio delle Lingue a scuola: tra sfide e criticità. In: Gori, Federica (ed.): Il Portfolio delle Lingua nell'Università italiana: student e aurtonomia. Trieste: Edizioni Università di Trieste, 15-24.

Mariani, Luciano; Tomai, Paola (2005): Il Portfolio delle Lingue. Metodologie, proposte, esperienze. Roma: Carocci.

Oxford, Rebecca L. (1990): Language Learning Strategies: What Every Teacher Should Know. Boston: Heinle \& Heinle Publishers.

Raimes, Ann (1991): Out of the Woods: Emerging Traditions in the Teaching of Writing. In: TESOL Quarterly 25/3, 40-63.

Rollinson, Paul (2005): Using peer feedback in the ESL writing class. In: ELT Journal 59/1, 23-30.

Sisamakis, Manolis (2010): The motivational potential of the European Language Portfolio. In: O’Rourke, Breffni; Carson, Lorna (eds.): Language Learner Autonomy: Policy Curriculum, Classroom. A Festschrift in Honour of David Little. Bern: Lang, 352-371.

Tribble, Christopher (1996): Writing. Oxford: Oxford University Press.

Università della Calabria (2003): Il Portfolio delle Lingue 40.2003. Arcavacata di Rende: Centro Editoriale e Librario.

Ushioda, Ema (2003): Motivation as a socially mediated process. In: Little, David; Ridley, Jennifer; Ushioda, Ema (eds.): Learner Autonomy in the Foreign Language Classroom: Teacher, Learner, Curriculum and Assessment. Dublin: Authentik, 3-5.

Westhoff, Gerard (2001): The European Language Portfolio as an instrument for documenting learning experiences - implementing the pedagogical function or how hard can we make the soft pages? In: Kohonen, Viljo; Westhoff, Gerard (eds.): Enhancing the Pedagogical Aspects of the European Language Portfolio (ELP). Strasbourg: Council of Europe, 32-53. https://rm.coe.int/1680459fa2 [10.02.2019]. 
Wingate, Ursula (2012): 'Argument!' helping students understand what essay writing is about. In: Journal of English for Academic Purposes 11/2, 145-154.

Zamel, Vivian (1987): Recent research on writing pedagogy. In: TESOL Quarterly 21/4, 697-715. 